\title{
Metabolic disorders during pregnancy and postpartum cardiometabolic risk
}

\author{
Angelo Maria Patti', Kalliopi Pafili ${ }^{2}$, Nikolaos Papanas ${ }^{2}$ and Manfredi Rizzo' \\ 'Department of Internal Medicine and Medical Specialties, University of Palermo, Palermo, Italy \\ ${ }^{2}$ Diabetes Centre, Second Department of Internal Medicine, Democritus University of Thrace, University Hospital of Alexandroupolis, \\ Alexandroupolis, Greece \\ Correspondence should be addressed to A M Patti: pattiangelomaria@gmail.com
}

\begin{abstract}
Hormonal changes during pregnancy can trigger gestational diabetes (GDM), which is constantly increasing. Its main characteristic is pronounced insulin resistance, but it appears to be a multifactorial process involving several metabolic factors; taken together, the latter leads to silent or clinically evident cardiovascular (CV) events. Insulin resistance and central adiposity are of crucial importance in the development of metabolic syndrome, and they appear to correlate with CV risk factors, including hypertension and atherogenic dyslipidaemia. Hypertensive disease of pregnancy (HDP) is more likely to be an accompanying co-morbidity in pregnancies complicated with GDM. There is still inconsistent evidence as to whether or not co-existent GDM and HDP have a synergistic effects on postpartum risk of cardiometabolic disease; however, this synergism is becoming more accepted since both these conditions may promote endothelial inflammation and early atherosclerosis. Regardless of the presence or absence of the synergism between GDM and HDP, these conditions need to be dealt early enough, in order to reduce CV morbidity and to improve health outcomes for both women and their offspring.
\end{abstract}

\author{
Key Words \\ - cardiovascular risk \\ - gestational diabetes \\ - hypertension \\ - metabolic syndrome
}

\section{Introduction}

There are several pregnancy indices of hormonal changes (such as oestrogens, progesterone, corticotropin-releasing hormone, cortisol, human placental growth hormone and human placental lactogen) that are implicated in the development of gestational diabetes (GDM) cases (1). Epidemiological evidence has consistently shown that among mothers with prior history of GDM, 30-84\% of them had GDM recurrence in subsequent pregnancies (2), $20-40 \%$ developed metabolic syndrome (MetS) within $2-20$ years $(3,4)$ and $17-63 \%$ developed type 2 diabetes mellitus (T2DM) and obesity within 5-16 years $(5,6,7)$. Longitudinal studies have shown that women with prior GDM and obesity were at higher risk to develop MetS compared with those without such metabolic history (8), and these women with prior GDM and obesity had

http://www.endocrineconnections.org https://doi.org/10.1530/EC-18-0130

(c) 2018 The authors Published by Bioscientifica Ltd relatively higher values of anthropometric parameters (such as BMI and waist circumference), blood pressure, glucose, homeostatic model assessment, insulin, C-peptide and fibrinogen, together with lower HDL-C levels (9).

Insulin resistance and central adiposity are of crucial importance in the development of MetS, and they appear to correlate with cardiovascular (CV) risk factors, including hypertension, atherogenic dyslipidaemia and glucose intolerance. The underlying mechanism of GDM is mainly pronounced insulin resistance (1). However, other factors, such as race, ethnicity, environmental and genetic factors (10), appear to contribute to the development of silent or clinical CV events. Interestingly, hypertensive disease of pregnancy (HDP) is very likely to be an accompanying co-morbidity in pregnancies

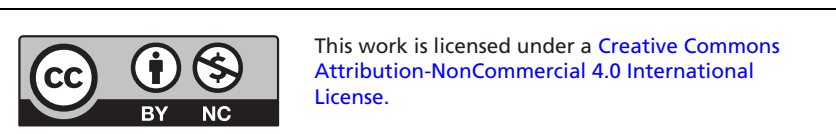


complicated with GDM $(11,12,13)$. Indeed, both these gestational complications share common risk factors such as maternal age, parity and pre-pregnancy BMI. Arguably, they may also share underlying mechanisms predisposing to subsequent recurrence of pregnancy complications and postpartum cardiometabolic disorders $(14,15,16,17,18)$.

However, it may also be true that HDP and GDM are the result of inherent susceptibility to cardiovascular disease (CVD). Mothers who were obese or had a personal history of chronic hypertension or diabetes before pregnancy are more likely to develop HDP or GDM (19, $20,21)$, and family history of CV risk is closely related to future CVD $(22,23)$.

\section{Is there a synergistic effect of GDM and HDP on postpartum cardiometabolic risk?}

It has been reported that there is a significant link between pregnancy complications (GDM and HDP) and CVD later in life $(18,24)$, since HDP and GDM may promote endothelial inflammation and early atherosclerosis independently of underlying conditions $(25,26,27,28,29,30)$. HDP and GDM also negatively impact on inflammatory biomarkers, including higher levels of plasminogen activator inhibitor-1, adiponectin, C-reactive protein, leptin and TNF alpha (1, 14). Importantly, these inflammatory biomarkers play an important role beyond their role in diabetes, insulin resistance, visceral obesity, CVD and hypertension (32, 33). Moreover, GDM and HDP are linked with elevated LDL-C and small dense LDL particles, which are implicated in CVD $(31,34)$.

Even though GDM and HDP may co-exist in pregnancies of the same mothers and are associated with $\mathrm{CV}$ risk, some controversy remains as to whether or not co-existent GDM and HDP have a synergistic effect to the risk of postpartum cardiometabolic disease (13). GDM or HDP is associated with a 15-fold higher risk in postpartum diabetes, with a sixfold greater risk of postpartum hypertension and a $40 \%$ risk increase for CVD mortality in the mothers (35). Meta-analyses have demonstrated that GDM is associated with a sevenfold higher risk of T2DM in affected mothers, and HDP is associated with a double risk of postpartum diabetes $(5,26)$. It has also been shown that a prior GDM can enhance the risk of having not only T2DM but also CVD, independently (36).

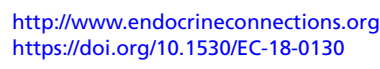

Interestingly, the study of Li et al. (37) shows that GMD and HDP contribute independently and not synergistically to the postpartum cardiometabolic risk, and this was somewhat unexpected, given the accumulating evidence $(35,36,37)$ that suggest that these conditions interplay in increasing the risk of diabetes, hypertension and CVD later in the mothers' lives as well as in their offspring $(10,26,38)$. There are some potential limitations in the study of Li et al. that need to be briefly discussed (37). First, the small cohort of subjects and the relative brief follow-up period. In addition, GDM cases may be somewhat misclassified because the diabetes diagnosis required fasting and/or the 2-h glucose testing after a $75 \mathrm{~g}$ oral glucose intake. Further, the data on GDM and HDP history were based on self-reports only. Finally, as already highlighted by the authors, since some mothers with an episode of GDM and/or HDP did not or were not able to conceive, subsequently, these findings could have underestimated their risks.

It is well known in literature that women with GMD and HDP are more prone to MetS $(39,40,41)$, and they appear to transmit an increased risk to the offspring through vertical transmission (8). Thus, it seems that women with GMD and HDP create an adverse metabolic memory (42).

\section{Conclusion}

Women who have had GDM and/or HDP are now recognised to carry a high risk of CVD and, regardless of the presence or absence of the synergism between GDM and HDP, they need to be followed very carefully. Indeed, the American Heart Association recommends longterm surveillance and management of $\mathrm{CV}$ risk factors in women with these pregnancy-related complications $(43,44)$. Of note, many women with GDM have later in life an undiagnosed T2DM (45) and, therefore, increased awareness of GDM and HDP is needed. In addition, postpartum screening tools and biomarkers of subsequent risk are very helpful in long-term follow-up.

\section{Declaration of interest}

All authors declare that there is no conflict of interest that could be perceived as prejudicing the impartiality of this editorial. This editorial was written independently. The authors have given talks, attended conferences and participated in advisory boards and trials sponsored by various pharmaceutical companies. 
15 Vambergue A, Nuttens MC, Goeusse P, Biausque S, Lepeut M \& Fontaine P. Pregnancy induced hypertension in women with gestational carbohydrate intolerance: the diagest study. European Journal of Obstetrics, Gynecology, and Reproductive Biology 2002102 31-35. (https://doi.org/10.1016/S0301-2115(01)00556-5)

\section{Funding}

This work did not receive any specific grant from any funding agency in the public, commercial or not-for-profit sector.

\section{References}

1 Ben-Haroush A, Yogev Y \& Hod M. Epidemiology of gestational diabetes mellitus and its association with Type 2 diabetes. Diabetic Medicine 200421 103-113. (https://doi.org/10.1046/j.14645491.2003.00985.x

2 Kim C, Berger DK \& Chamany S. Recurrence of gestational diabetes mellitus: a systematic review. Diabetes Care 200730 1314-1319. (https://doi.org/10.2337/dc06-2517)

3 Gunderson EP, Jacobs DR Jr, Chiang V, Lewis CE, Feng J, Quesenberry CP Jr \& Sidney S. Duration of lactation and incidence of the metabolic syndrome in women of reproductive age according to gestational diabetes mellitus status: a 20-year prospective study in CARDIA (Coronary Artery Risk Development in Young Adults). Diabetes 201059 495-504. (https://doi.org/10.2337/db09-1197)

4 Lauenborg J, Mathiesen E, Hansen T, Glümer C, Jørgensen T, BorchJohnsen K, Hornnes P, Pedersen O \& Damm P. The prevalence of the metabolic syndrome in a Danish population of women with previous gestational diabetes mellitus is three-fold higher than in the general population. Journal of Clinical Endocrinology and Metabolism 200590 4004-4010. (https://doi.org/10.1210/jc.2004-1713)

5 Bellamy L, Casas JP, Hingorani AD \& Williams D. Type 2 diabetes mellitus after gestational diabetes: a systematic review and metaanalysis. Lancet 2009373 1773-1779. (https://doi.org/10.1016/ S0140-6736(09)60731-5)

6 Hanna FW \& Peters JR. Screening for gestational diabetes; past, present and future. Diabetic Medicine 200219 351-358. (https://doi. org/10.1046/j.1464-5491.2002.00684.x)

7 Lee AJ, Hiscock RJ, Wein P, Walker SP \& Permezel M. Gestational diabetes mellitus: clinical predictors and long-term risk of developing type 2 diabetes: a retrospective cohort study using survival analysis. Diabetes Care 200730 878-883. (https://doi.org/10.2337/dc06-1816)

8 Malcolm J. Through the looking glass: gestational diabetes as a predictor of maternal and offspring long-term health. Diabetes/ Metabolism Research and Reviews 201228 307-311. (https://doi. org/10.1002/dmrr.2275)

9 Bo S, Monge L, Macchetta C, Menato G, Pinach S, Uberti B \& Pagano G. Prior gestational hyperglycemia: a long-term predictor of the metabolic syndrome. Journal of Endocrinological Investigation 2004 27 629-635. (https://doi.org/10.1007/BF03347494)

10 Rizvi AA, Cuadra S, Nikolic D, Giglio RV, Montalto G \& Rizzo M. Gestational diabetes and the metabolic syndrome: can obesity and small, dense low density lipoproteins be key mediators of this association? Current Pharmaceutical Biotechnology 201415 38-46. (https://doi.org/10.2174/1389201015666140330193653)

11 Dukler D, Porath A, Bashiri A, Erez O \& Mazor M. Remote prognosis of primiparous women with preeclampsia. European Journal of Obstetrics, Gynecology and Reproductive Biology 200196 69-74. (https://doi.org/10.1016/S0301-2115(00)00392-4)

12 Xiong X, Saunders LD, Wang FL \& Demianczuk NN. Gestational diabetes mellitus: prevalence, risk factors, maternal and infant outcomes. International Journal of Gynaecology and Obstetrics 200175 221-228. (https://doi.org/10.1016/S0020-7292(01)00496-9)

13 Ehrenthal DB, Maiden K, Rogers S \& Ball A. Postpartum healthcare after gestational diabetes and hypertension. Journal of Women's Health 201423 760-764. (https://doi.org/10.1089/jwh.2013.4688)

14 Solomon CG \& Seely EW. Brief review: hypertension in pregnancy: a manifestation of the insulin resistance syndrome? Hypertension 2001 37 232-239. (https://doi.org/10.1161/01.HYP.37.2.232)
16 Damm P, Houshmand-Oeregaard A, Kelstrup L, Lauenborg J, Mathiesen ER \& Clausen TD. Gestational diabetes mellitus and longterm consequences for mother and offspring: a view from Denmark. Diabetologia 201659 1396-1399. (https://doi.org/10.1007/s00125016-3985-5)

17 Gongora MC \& Wenger NK. Cardiovascular complications of pregnancy. International Journal of Molecular Sciences 201516 23905-23928. (https://doi.org/10.3390/ijms161023905)

18 Naderi S, Tsai SA \& Khandelwal A. Hypertensive disorders of pregnancy. Current Atherosclerosis Reports 201719 15. (https://doi. org/10.1007/s11883-017-0648-z)

19 Romundstad PR, Magnussen EB, Smith GD \& Vatten LJ. Hypertension in pregnancy and later cardiovascular risk: common antecedents? Circulation 2010122 579-584. (https://doi.org/10.1161/ CIRCULATIONAHA.110.943407)

20 Qiu C, Williams MA, Leisenring WM, Sorensen TK, Frederick IO, Dempsey JC \& Luthy DA. Family history of hypertension and type 2 diabetes in relation to preeclampsia risk. Hypertension $2003 \mathbf{4 1}$ 408-413. (https://doi.org/10.1161/01.HYP.0000056996.25503.F5)

21 Geelhoed JJ, Fraser A, Tilling K, Benfield L, Davey Smith G, Sattar N, Nelson SM \& Lawlor DA. Preeclampsia and gestational hypertension are associated with childhood blood pressure independently of family adiposity measures: the Avon Longitudinal Study of Parents and Children. Circulation 2010122 1192-1199. (https://doi. org/10.1161/CIRCULATIONAHA.110.936674)

22 D'Agostino RB Sr, Vasan RS, Pencina MJ, Wolf PA, Cobain M, Massaro JM \& Kannel WB. General cardiovascular risk profile for use in primary care: the Framingham Heart Study. Circulation 2008117 743-753. (https://doi.org/10.1161/CIRCULATIONAHA.107.699579)

23 Wilson PW, D'Agostino RB, Levy D, Belanger AM, Silbershatz H \& Kannel WB. Prediction of coronary heart disease using risk factor categories. Circulation 199897 1837-1847. (https://doi. org/10.1161/01.CIR.97.18.1837)

24 Edalat B, Sharifi F, Badamchizadeh Z, Hossein-Nezhad A, Larijani B Mirarefin M \& Fakhrzadeh H. Association of metabolic syndrome with inflammatory mediators in women with previous gestational diabetes mellitus. Journal of Diabetes and Metabolic Disorders 201312 8. (https://doi.org/10.1186/2251-6581-12-8)

25 Gunderson EP, Chiang V, Pletcher MJ, Jacobs DR, Quesenberry CP, Sidney S \& Lewis CE. History of gestational diabetes mellitus and future risk of atherosclerosis in mid-life: the Coronary Artery Risk Development in Young Adults study. Journal of the American Heart Association 20143 e000490. (https://doi.org/10.1161/ JAHA.113.000490)

26 Bellamy L, Casas JP, Hingorani AD \& Williams DJ. Pre-eclampsia and risk of cardiovascular disease and cancer in later life: systematic review and meta-analysis. BMJ 2007335 974. (https://doi. org/10.1136/bmj.39335.385301.BE)

27 Rodie VA, Freeman DJ, Sattar N \& Greer IA. Pre-eclampsia and cardiovascular disease: metabolic syndrome of pregnancy? Atherosclerosis 2004175 189-202. (https://doi.org/10.1016/j. atherosclerosis.2004.01.038)

28 Carpenter MW. Gestational diabetes, pregnancy hypertension, and late vascular disease. Diabetes Care 200730 (Supplement 2) 246-250. (https://doi.org/10.2337/dc07-s224)

29 Yinon Y, Kingdom JC, Odutayo A, Moineddin R, Drewlo S, Lai V, Cherney DZ \& Hladunewich MA. Vascular dysfunction in women with a history of preeclampsia and intrauterine growth restriction: insights into future vascular risk. Circulation 2010122 1846-1853. (https://doi.org/10.1161/CIRCULATIONAHA.110.948455) http://www.endocrineconnections.org https://doi.org/10.1530/EC-18-0130 (c) 2018 The authors Published by Bioscientifica Ltd
This work is licensed under a Creative Commons Attribution-NonCommercial 4.0 International License. 
30 Mrizak I, Arfa A, Fekih M, Debbabi H, Bouslema A, Boumaiza I, Zaouali M, Khan NA \& Tabka Z. Inflammation and impaired endothelium-dependant vasodilatation in non obese women with gestational diabetes mellitus: preliminary results. Lipids in Health and Disease 201312 93. (https://doi.org/10.1186/1476-511X-12-93)

31 Qiu C, Rudra C, Austin MA \& Williams MA. Association of gestational diabetes mellitus and low-density lipoprotein (LDL) particle size. Physiological Research 200756 571-578.

32 Ridker PM. Inflammatory biomarkers and risks of myocardial infarction, stroke, diabetes, and total mortality: implications for longevity. Nutrition Reviews 200765 253-259. (https://doi. org/10.1301/nr.2007.dec.S253-S259)

33 Rizvi AA. Hypertension, obesity, and inflammation: the complex designs of a deadly trio. Metabolic Syndrome and Related Disorders 2010 8 287-94. (https://doi.org/10.1089/met.2009.0116)

34 Brewster S, Zinman B, Retnakaran R \& Floras JS. Cardiometabolic consequences of gestational dysglycemia. Journal of the American College of Cardiology 201362 677-684. (https://doi.org/10.1016/j. jacc.2013.01.080)

35 Pace R, Brazeau AS, Meltzer S, Rahme E \& Dasgupta K. Conjoint associations of gestational diabetes and hypertension with diabetes, hypertension, and cardiovascular disease in parents: a retrospective cohort study. American Journal of Epidemiology 2017186 1115-1124. (https://doi.org/10.1093/aje/kwx263)

36 Bentley-Lewis R. Late cardiovascular consequences of gestational diabetes mellitus. Seminars in Reproductive Medicine 200927 322-329. (https://doi.org/10.1055/s-0029-1225260)

37 Li LJ, Aris IM, Su LL, Chong YS, Wong TY, Tan KH \& Wang JJ. Effect of gestational diabetes and hypertensive disorders of pregnancy on postpartum cardiometabolic risk. Endocrine Connections 20187 433-442. (https://doi.org/10.1530/EC-17-0359)

38 Nolan CJ, Damm P \& Prentki M. Type 2 diabetes across generations from pathophysiology to prevention and management. Lancet 2011 378 169-181. (https://doi.org/10.1016/S0140-6736(11)60614-4)

39 Sim JH, Chung D, Lim JS, Lee MY, Chung CH, Shin JY \& Huh JH. Maternal age at first delivery is associated with the risk of metabolic syndrome in postmenopausal women: from 2008-2010 Korean National Health and Nutrition Examination Survey. PLoS ONE 201510 e0127860. (https://doi.org/10.1371/journal. pone.0127860)

40 Sullivan SD, Umans JG \& Ratner R. Gestational diabetes: implications for cardiovascular health. Current Diabetes Reports 201212 43-52. (https://doi.org/10.1007/s11892-011-0238-3)

41 Rizzo M, Berneis K, Altinova AE, Toruner FB, Akturk M, Ayvaz G, Rini GB, Spinas GA \& Arslan M. Atherogenic lipoprotein phenotype and LDL size and subclasses in women with gestational diabetes. Diabetic Medicine 200825 1406-1411. (https://doi.org/10.1111/ j.1464-5491.2008.02613.x)

42 Yessoufou A \& Moutairou K. Maternal diabetes in pregnancy: early and long-term outcomes on the offspring and the concept of 'metabolic memory'. Experimental Diabetes Research 20112011 218598. (https://doi.org/10.1155/2011/218598)

43 Lloyd-Jones DM, Hong Y, Labarthe D, Mozaffarian D, Appel LJ, Van Horn L, Greenlund K, Daniels S, Nichol G, Tomaselli GF, et al. Defining and setting national goals for cardiovascular health promotion and disease reduction: the American Heart Association's strategic Impact Goal through 2020 and beyond. Circulation 2010121 586-613. (https://doi.org/10.1161/ CIRCULATIONAHA.109.192703)

44 Mosca L, Benjamin EJ, Berra K, Bezanson JL, Dolor RJ, LloydJones DM, Newby LK, Piña IL, Roger VL, Shaw LJ, et al. Effectivenessbased guidelines for the prevention of cardiovascular disease in women - 2011 update: a guideline from the American Heart Association. Circulation 2011123 1243-1262. (https://doi. org/10.1161/CIR.0b013e31820faaf8)

45 International Association of Diabetes and Pregnancy Study Groups Consensus Panel, Metzger BE, Gabbe SG, Persson B, Buchanan TA, Catalano PA, Damm P, Dyer AR, Leiva Ad, Hod M, et al. International association of diabetes and pregnancy study groups recommendations on the diagnosis and classification of hyperglycemia in pregnancy. Diabetes Care 201033 676-682. (https://doi.org/10.2337/dc09-1848)

Received in final form 23 April 2018

Accepted 30 April 2018

Accepted Preprint published online 30 April 2018 http://www.endocrineconnections.org https://doi.org/10.1530/EC-18-0130 (c) 2018 The authors Published by Bioscientifica Ltd

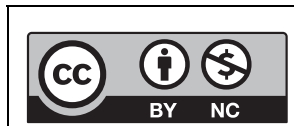

This work is licensed under a Creative Commons Attribution-NonCommercial 4.0 International License. 